\title{
Decoding the Narrative Structure of E. E. Cummings' Visual Love Poetry: A Stylistic Analysis of Foregrounding in "All in Green Went My Love Riding"
}

\author{
By Nashwa Elyamany*
}

\begin{abstract}
E. E. Cummings is known for his bold experimentation with poetic forms and eccentric deviation from linguistic norms in his visual love poetry. The peculiar distribution of lines and unerring rhetorical skills are given special zest and prominence by virtue of his twin obsessions: poetry and painting. The current study is premised on two tenets: first, foregrounding is the dominant feature of Cummings' narrative poetry; second, the multitude of semiotic resources and their division of labor in his poetic texts, coupled with the wittily expressed attitudinal values, add new layers of discourse that are worthy of investigation. The aim of the research endeavor at hand is to unravel the poetic effects of the foregrounding devices employed in the love poem "all in green went my love riding". To this end, the meta-functions of Systemic Functional Theory and Visual Grammar are used as the basis of analysis. Various types of deviation and regular patterns, in terms of repetition and parallelism, are combined to enable smooth narrative flow while engaging the reader in the setting and the action from start to finish. Linguistic deviation effectively serves foregrounding in the poem. This, in turn, tempts readers to reach valid interpretations of the poem overall. The poem is an exquisite mixing bowl of counter-grammatical devices and regularities within the syntactic texture of each of the fourteen stanzas. The researcher argues that even with the less deviant of Cummings' poems, textual and visual resources in the semiotic ensemble of the poetic text are carriers of potential meaning serving the overall structure of the narrative genre.
\end{abstract}

Keywords: E. E. Cummings, Foregrounding, Stylistic, Textual, Visual

\section{Introduction}

E. E. Cummings is held in high esteem in the field of American poetry. Among his fellows - Robert Frost, T. S. Eliot, Ezra Pound, William Carlos Williams, Wallace Stevens, and John Ashbery - Cummings is one of the most prolific and resourceful American poets of the twentieth century. Cummings is famous for his bold experimentation with poetic forms and eccentric deviation from linguistic norms in pursuit of creating an exclusive typography as well as perpetuating an individualized style that is difficult to emulate. He is known for his peculiar distribution of lines and unerring rhetorical skills, remarkable in his love poems, as well as his wit and zestfulness, so prominent in his twin obsessions poetry and painting.

The main reason for Cummings' positive reception and popularity among readers is the fact that he is one of the very few poets who write about love and sexuality in an ingenuously direct, novel, and lighthearted fashion. His exquisite linguistic agility serves his lofty vision of love in such unprecedented ways that he is celebrated for his pertinent and effective deviation from conventions on all levels of the language. Only a handful of poets are skillfully able to defy linguistic

\footnotetext{
* Head of Languages Department, Arab Academy for Science, Technology and Maritime Transport (AASTMT), Egypt.
} 
norms to this degree, yet none approach his ability. For scholars interested in describing and scrutinizing the aesthetic value and use of language, the visual love poetry of Cummings is a rich arena and an irresistible challenge.

\section{Literature Review}

The poetry of E. E. Cummings appeals to researchers and scholars of various disciplines, who are linked through being stylisticians. His eccentric treatment of the English language is so intriguing and baffling that it calls for careful exploration, interpretation, and evaluation. Cummings' linguistic idiosyncrasies are attributed to his twin obsessions which reveal themselves in textual and visual modes in almost all his works. Of all his peculiarities, linguistic deviation is his most prominent means of realizing foregrounding and achieving aesthetic value.

A large body of research in the literature to date is dedicated to stylistic analyses of Cummings' poetry and capitalizes on observable patterns on different linguistic levels (Espák 2012, Moe 2011, Wang 2012). Most studies, however, tackle Cummings' poetry only anecdotally, placing emphasis on the meticulously selected semantic, syntactic, lexical, and graphological deviations that produce powerful visual impressions on the readers. Examples are studies on: syntax (Berutti 1970, Cureton 1979a, 1979b, Fairley 1971, 1975, Lord 1966); morphology (Cureton 1979b, Fairley 1975); typography (González Mínguez 2010, Tartakovski 2009); unconventional spelling (Alfandary 2002, Heusser 1997, von Abele 1955, Webster 1995); newyorkese in Cummings' poems (Friedman 1960); unorthodox orthography and voice rendering (Cureton 1986); and punctuation marks (GómezJiménez 2015a, 2015b, 2017). Literary scholars, on the other hand, have made considerable contributions to the understanding of Cummings' themes, imageries, visual representation, historical and biographical background, and traditional poetic devices, but have devoted little time to the more deviant aspects of his language. As a result, the effectiveness and systematization of a large portion of Cummings' deviant language remains unexplained.

\section{Theoretical Background}

\section{Foregrounding in Poetry}

In broad terms, stylistics is the study of literary discourse in relation to the linguistic forms writers purposefully employ in their literary works. Operating on all linguistic levels, stylisticians are preoccupied with the analysis of both style and stylistic variation. Poetic style, as a deviant form of the norm, relates to all the eccentric linguistic inclinations permitted by poetic license. In Stylistics, the notion of foregrounding, the term advanced by the Prague School of Linguistics, is effectively referred to as "artistically motivated deviation" by Leech and Short. "Foregrounded features are the parts of the text which the author, consciously or unconsciously, is signalling as crucial to our understanding of what he has written ..." (Short 1996: 36). 
Foregrounding theory fundamentally advocates that poetic language deviates from linguistic norms and this deviation hinders communication (see e.g., Kidder 1979, van Peer 1986, 1987, Miall and Kuiken 1994). Nonetheless, native speakers of a language render these oddities stylistically marked and highly communicative. Apart from being noticeably visible, these perceived incongruities serve as an attention-drawing device in a literary text, which prompt readers to interpret them. Having spotted such deviant aspects, curious readers ponder the choice of formulation. Short (1996: 36-58) argues that deviation occurs on seven levels: discoursal (e.g., beginning in the middle); semantic (e.g., paradox, metaphor, etc.); lexical (e.g., neologism, functional conversation, etc.); grammatical (e.g., inversion, ellipsis, etc.); morphological (e.g., playing with morphemes such as in the poetry of Cummings); phonological (e.g., alliteration, assonance, etc.); and graphological (e.g., oddities in the written presentation of the text).

In literature, foregrounding is created via the construction and exploitation of patterns and systems within language use, and perceived deviation from those patterns. Parallels can be fashioned through patterning and repetition of structures (as in rhyme schemes and repeated syntactic positioning), prompting the reader to seek semantic associations and interpretative links between the paralleled features. That is, foregrounding is realized by linguistic deviation and parallelism (Leech 2008, Leech and Short 2007). Short (1996) draws upon a clear division between internal and external deviation. Internal deviations are identified within the text itself, whereas external deviations relate to the established norms of the language, or the literary genre.

\section{Multimodal Discourse Analysis}

Multimodal Discourse Analysis (MDA) is an evolving paradigm extensively deliberated on in the studies of discourse and semiotics. MDA adds new dimensions to the study of language relative to a multitude of semiotic resources, notably images, symbols, gestures, motions, and sound (O'Halloran 2011). It is noteworthy that a multimodal account does not lay emphasis on one semiotic feature at the expense of another; rather, it identifies the wide spectrum of meaning momentums and potentials such semiotic features afford when co-deployed in the process of meaning-making.

Halliday (1978) purports that texts simultaneously fulfill three broad metafunctions - the ideational, the interpersonal, and the textual - which are mostly realized through the systems of transitivity, mood, and thematic structure, respectively. Parallel to Halliday's are Kress and van Leeuwen's (1996, 2006) meta-functions that their Visual Grammar model largely encompass. According to them, in the same manner as does language, images fulfill the meta-functions of representing the experiential world (i.e., representational meaning), the interaction between the participants represented in a visual design and its viewers (i.e., interactive meaning), and the compositional arrangements of visual resources (i.e., compositional meaning). In this study, following Halliday and Matthiessen's (2014) Systemic-Functional Grammar (SFG), the systems of "transitivity", "mood", and "thematic structure" are examined in the textual analysis. Based on 
Kress and van Leeuween's (1996, 2006) Visual Grammar (VG), the visual analysis examines: the representational meaning in terms of "narrative" processes; the interactive meaning in light of "size of frame" (social distance); and the compositional meaning with respect to "information value" (placement), "framing" (connectedness), and "salience".

Born within the framework of critical discourse studies, multimodality has developed into a rapidly emerging interdisciplinary field (Jewitt 2005). The interplay of poetry and multimodality is indisputable, particularly in the visual poetry of Cummings. Only in recent years has a fair amount of research been geared toward the study of multimodal theories on poetry interpretation, and thus far Cummings' visual poetry has received inadequate attention (Wang 2012). Although Visual Grammar is primarily developed for the study of static images, the model can still be put to test in the works of Cummings, particularly his visual poems with their extreme deviations and eccentricities. This is where the present study fills the gap in the literature to date and is, therefore, a keystone for a systematic multimodal-stylistic analysis of E. E. Cummings' "all in green went my love riding" (1916) that the researcher embarks on. It is part of a project initiated by the researcher to revolutionize the study of Cummings' visual poetry in multimodal terms, hence drawing on a myriad of vibrant patterns of meaning.

\section{Research Questions}

Premised on the assumption that foregrounding is the dominant feature of poetry, the current study aims to answer the following research questions:

1. What are the poetic effects of the linguistic devices employed for foregrounding in Cummings' "all in green went my love riding"?

2. What are the affordances of a Systemic-Functional Multimodal Discourse Analysis to Cummings' "all in green went my love riding"?

\section{General Interpretation of the Poem}

Cummings studied classical languages at Harvard, but he spoke often in his poems the medieval tongue of courtly love. Nowhere does he weave more gracefully these ancient and merrily old threads than in the textual tapestry of "all in green went my love riding" (see Appendix A). This luminous and initially perplexing text is a love poem. Although the fact is not overtly elucidated, it is an elaborate metaphor about courtship and undertaking the consequences thereof. It is an allegory to and a subtle narration of an ancient fable featuring the Roman goddess of the hunt, riding off at the break of dawn in the company of her sacred animals.

The female hunter throws down the gauntlet regarding the speaker's venture to pursue her and so she has him, metaphorically, killed. The poem is set in fourteen stanzas, each of which graphically chronicles a different phase of the 
grand chase, i.e., courtly love. "All in green went my love riding" is not too complex a poem to grasp in terms of its underlying theme. What is challenging for readers is to relate the plethora of stylistic and multimodal features that Cummings gracefully interlaces in the poem to plausible explanations.

Indeed, Cummings takes all kinds of detours along the way, lingering to describe the running deer, the crouching hounds, and the valleys through which they journey. There seems to be a twofold thread weaving through the poem: a narrative account of human love and a dazzling exhibition of natural beauty. Readers begin to appreciate the theme when gazing at the most foregrounded features of the poem; that is, the bits of the poem that stand out because they seem unusual. "All in green went my love riding" is a fine exemplar of Cummings' extreme boldness in manipulating the conventions of the English language and deviating from the norms in attempt to conceal more complex shades of meaning than found in merely a simple ballad. Indeed, the dexterous use of foregrounding devices and semiotic resources helps to elevate the theme of the poem in unprecedented ways.

\section{Analysis}

\section{Stylistic Analysis}

Unequivocally, a linguistic deviation is a disruption of the normal processes of communication, leaving a gap in one's comprehension of the text. Leech (1969: 10-12) posits that any deviation from linguistic norms leads to reactions of bewilderment. This deviation, nonetheless, can be rendered significant only when readers exert conscious effort to perceive some deeper connection that compensates for the discernible oddity. A deviant linguistic feature a priori does not exist in isolation; rather, it intermingles with other linguistic cues on intratextual and extra-textual planes. In this section, the researcher examines deviation on the discoursal, graphological, semantic, and syntactic levels, delving into how they contour the emotional experience of courtly love. To facilitate the analysis, each line of the poem is numbered (see Appendix A). The analysis is restricted to the linguistic features that are relevant and prominent. Where appropriate, plausible interpretations associated with each feature are introduced for subsequent evaluation of the poem.

In discourse terms, researchers can adequately account for much poetry and deal with it via the "direct address" mode - i.e., the prototypical addressermessage-addressee situation. However, this is not always the case, particularly in the poem under study. It is quite ambiguous whether the addresser in "all in green went my love riding" is the poet or a persona. Is Cummings narrating a personal experience by means of an allusion to an old myth? Is he placing himself in the position of a lover he knows, detailing how he is a victim of love? Is he the mouthpiece and ambassador of love by and large? Although the poem takes the first person point of view, as indicated by the possessive $m y$ in "all in green went my love riding" and "my heart fell dead before", readers are baffled and have no 
clue if the speaker is the poet or some persona. Apart from anything else, the speaker in the poem unveils the multiple phases of the narrative as though he were an observer and a commentator on the scene.

The multiple-addresser mode instantiated by Cummings is well deployed in the poem at hand. Cummings is interested in the entirety of language and in the full range of its potential rather than in its narrow, conceptual aspect. He manages to engage readers in the storyline, calling their attention to the fine details of the chase as the poem unfolds by means of incarnating all potential lovers in the broad sense of the word. Cummings is a strong advocate of human rights and, other than his desire to break the conventions of the language, this type of discoursal deviation, at the macro level, is a way of foregrounding humility and equality among people.

An interesting typographic convention of poetry, one in which both external and internal deviation may be produced, governs the use of initial letters in a line. The general practice is to begin each line of a poem with a capital letter, producing in this way an external deviation. To make poetic texts more familiar to the naked eye of modern readers in the twentieth century, the typographic idiosyncrasies have been normalized in Cummings' poetry as will be seen in what follows. In breaking with the tradition in "all in green went my love riding", he goes on to exploit his convention by beginning an occasional (though not a random) line with a capital, thus producing an internal deviation. Punctuation, typeface, line arrangement, and spelling are all physical features that participate in the creation of meaning. Leech and Short (1981: 131) advocate: Graphological deviation is a relatively minor and superficial part of style, concerning such matters as spelling, capitalization, hyphenation, italicization, and paragraphing. Such matters are determined conventionally by syntax and become noticeably expressive only when a writer makes a graphological choice, which is to some degree marked or unconventional, such as a deliberate misspelling.

To Cummings, orthography shapes the impromptu experience of love. A cursory look at "all in green went my love riding" reveals that all the lines of the poem (not excluding the title) are in lower-case except for line-initials of each stanza. Cummings' practice represents a deviation not only from the poetic convention but from the external norm of ordinary language use as well. He resorts to capitalization, but he de-automatizes its usage in order to make a poetic choice out of it. To him, each stanza is a unity detailing a different phase of the chase, marked as it is by the initial capital in the first line of each. He disregards typographic conventions to foreground the speaker's lover and the grand chase. Interestingly, full stops at the end of each stanza are mostly employed for rhythmical purpose. In brief terms, Cummings' effective breach of orthographic norms validates the fact that punctuation marks are amenable to appropriation, exploitation, and projection as shown in later examples as the analysis unfolds.

Metaphor in poetry, in its wider sense, is the process whereby literal absurdity leads the mind to comprehension on a figurative plane (Leech 1969). It is by far the most important single factor in that transcendence of the normal resources of communication by which poetic language is characterized. In "all in green went my love riding", several metaphors are deliberated by Cummings to draw 
memorable portraits of the beauty of the landscape and setting where the grand chase takes place. Examples are: "horse of gold", "silver dawn", "hounds... smiling", "merry deer", "arrow sang", "peaks ran", and "riding the echo". In fact, the poem is saturated with language that appreciates the beauty of the natural world, and the humans who trample through it.

Exquisitely, the very crux of "all in green went my love riding" is a pun and the pun happens to play upon the very relation between man and animal. The poem springs from an extended metaphor of the speaker's heart in the deer vividly described from start to finish. All the alliterative pairs of adjectives describing the deer might also be typically applied to human life, as in "swift sweet", "red rare", "tall tense", and "sleek slim". The last line of the poem, at its core, is a metaphor in "my heart fell dead", the speaker is not referring to literal death. Rather, he is relating it to the theme of courtly love. Cummings' unconventional presentation of verse leaves readers mesmerized in a world of spontaneity, liveliness, fantasy, and timelessness. The ebullient metaphors deftly interwoven in the verse are part and parcel of Cummings' aesthetics that foreground the theme of love.

Cummings particularly enjoys experimenting with the syntactic conventions of the English language. His poetry is suffused with odd grammar and disconcertingly strange word ordering. Inverted syntax is one prominent freedom Cummings enjoys in "all in green went my love riding". In line 1 of the poem, the subject-verb inversion is realized to foreground the dramatic effect. Repeating the same inverted structure in line 11 emphasizes the point that the act of riding (and in turn the chase) is the principal action in the poem. Another interesting instance of inversion is in lines 9 and 10, which should be read as line 10 then line 9 to conform to English syntax. The switch foregrounds the deer as the center of attention. Similarly, the inversion in lines 19 and 20 parallels that in lines 9 and 10; that is, to conform to English syntax, they should be read in a reversed sequence, where the arrows chase the deer. The reversed order in the aforementioned account draws readers' attention to the motion and perhaps the speed of the arrow targeting the deer, hence accelerating the scene and the imminent end.

In addition to the inverted syntax, impermissible structures are in use as in "be they" in "fleeter be they than dappled dreams", which should read "they are fleeter than dappled dreams". Not conjugating the verb "to be", the poet perpetuates the imagery of the running deer. The deer, in this sense, is in motion so far in the poem. The syntactic abnormality in this example is far from being a hindrance to communication. Intentionally, it conveys a bit of information - i.e., the progression or timelessness of the action, which the poet foregrounds. Similarly, in line 26, the verb "to be" is not conjugated but for a different purpose; "paler be they than daunting death" should be "they are paler than daunting death"; this deviation marks a shift in the deer's state. The deer appears to be paler than death, hence foreshadowing his looming tragic end. To sum up, Cummings' idiosyncratic grammar recurs in different stanzas of the verse to call readers' attention to the setting and the many actions taking place at different phases in the hunt scene. 


\section{Multimodal Analysis}

Cummings' penchant for linguistic estrangement, typographical play, and the creation of movement and experience make his poetic texts a rich arena for a multimodal analysis. In this section, the researcher unravels the textual and visual make-up of "all in green went my love riding", identifying the semiotic resources that advance foregrounding and further the theme of the poem.

In Hallidayan terms, the ideational meta-function is the "content function of language" (Halliday 2007: 183) and is primarily realized through the system of transitivity that details the very types of processes (material, mental, behavioral, etc.) that represent situations and events in the world. The transitivity choices in the poem point out how the participants in the poetic text are represented. Each two-line stanza in the poem is buzzing with action, depicting a different phase of the chase. There seems to be a clear pattern that is worth dwelling upon.

The majority of the processes are "material" in type, with the poet, his love, and the animals in her company as participants in the role of "actor". The material process verbs are put to good effect so as to fit into the adventurous scene, despite the fact that some of these verbs are used metaphorically with inanimate entities. Examples to note are "went my love riding", "hounds crouched", "the merry deer ran", "bugle sang", and "meadows ran". Static in this flux, an insistent refrain repeated once for each dog, are "four lean hounds crouched low and smiling". Unmoving, uncolored and perpetually still in the midst of all actions, these hounds are backgrounded to foreground the actions in the poem.

On a related note, the poet makes effective use of circumstantial adjuncts of different types: location (e.g., "on a great horse of gold"), place (e.g., "at a white water"), and manner (e.g., "horn at hip", "bow at belt", and "low and smiling"), falling into different places in the stanzas (at the beginning, or at the end). They all orchestrate to not only weave the ballad together, hence producing a unity, but to also sequence the transitivity choices made by the poet. The overall transitivity profile unravels the actions of the ballad one at a time and serves in foregrounding the grand chase.

The interpersonal meta-function, according to Halliday, is the "participatory function of language" and is primarily realized through the systems of mood. The poem is set in fourteen stanzas, each of which portrays a graphic phase of the chase, i.e., courtly love. The language of the poem parallels these phases, starting off with gentle imageries, ending up with creepy accounts. Each stanza, line, and word calls for illumination with respect to the context in which it occurs. Even though the poem is laced with ferocity, readers are flabbergasted when the actual prey turns out to be the lover. The poet recites the narrative through binoculars as though he were an observer and commentator on the scene. This, in turn, engages readers in the ballad, shortening the distance between the poet and readers, hence making them feel that they belong to the same discourse community, i.e., lovers at large.

Specific lines offer little difficulty, though. Shortly after a courtly start (the "green", "gold" and "silver" of stanza 1, which may fancifully suggest medieval illumination) the poem becomes ominous with suggested conflict. Stanza 2, 
juxtaposing sinister hounds and merry deer, sets sympathies as well as sides. Line 6 underscores them. When "my love" is identified as a hunter by the "cruel bugle" of line 10, a dilemma becomes apparent. With the second quatrain, the hunt quickens. Ground shifts from a "white water" to "level meadows" and a "gold valley". The equipment of the chase is the "famished arrow". The final ten lines bring to a climax both the chase and the dilemma. The ground rises to "sheer peaks" and a "green mountain". The tired deer, now within range, are "paler...than daunting death".

The implication of this allegoric hunt, the upshot of this mixture of tapestry, linear exposition, and graphic concept, lies in the poem's movement. From the outset, readers are caught in a dreamlike flux of color, landscape and even gender. In the half-light of dawn, "green", "gold", "silver", "red", and "white" flash past. Terrains alter, and even the deer changes from "roebuck" to "does" to "stags". This narrative technique is particularly useful in this poem because its frame effect, the suspense-creating discontinuity that forms and informs tapestry, snaps suddenly as a clicked shutter to reveal the hero's unexpected "death".

It is in the textual function that ideational and interpersonal meanings are actualized (Halliday 2007: 184) and essentially realized through the systems of cohesion and thematic structure. Pattern making is one of the striking features of poetic language that encompass the systems above. Pattern making in poetry can be called "extra-regularities" and a poet goes beyond the regular patterns of language for the sake of foregrounding. Numerous instances of lexical repetition are easily traced in the ballad. First, the title - being the first line of the poem takes the reader straight into the heart of the poem, with its sonic repetition, and the fascinating graphic portraits that recur throughout as the narrative flows. From the start, readers are at the heart of the scene, enjoying the ride and following the chase.

Stationary amidst this movement are "four lean hounds crouched low and smiling" - an insistent refrain in stanzas 2, 6, 10, and 14. As indicated earlier, representing them as motionless in the midst of all the buzzing actions foregrounds the hunting scene; the dogs are part of the setting signaling that a hunt is underway. A final striking instance of repetition is stanza 13, which is the same as stanza 1. While stanza 1 marks the beginning of the hunt, stanza 13 marks the closure of the story and the chase, bringing readers in a full circle. At this point of the poem, readers are left in anticipation of the end: will the chase end merrily or tragically? Repetition so far is employed to startle readers with unexpected twists in events.

From another angle, to organize the theme of the poem and the progression of the chase, the poet makes effective use of the theme and rheme. In English, the theme is realized by what is placed in the first position within the clause, and thus has a special status. What Cummings chooses to thematize in each stanza relates to the poet's love (e.g., "all in green", "horn at hip", and "bow at belt"), other participants in the scene (e.g., "four lean hounds", "four fleet does", "four tall stags", etc.) or comparatives that describe them (e.g., "fleeter", "softer", and "paler"). This pattern is intended as a constant gentle reminder of the peaceful company that escorts the speaker's love in the journey from start to finish. 
The representational meaning can be achieved through the visual construction of the nature of events, the objects and participants involved as well as the circumstances in which they occur. Visual poetry treats the page design as a canvas to represent the themes, participants, or emotions in multiple ways. The very typographical arrangement of "all in green went my love riding", while seemingly arbitrary, plays an indispensable role in setting the scene of the ballad and functions to reinforce the content of the ballad. In this poem, the representational meaning is realized by means of the narrative image. Graphically conceived, the poem is linear in structure. Its literal magic is prefigured and given context by the echo of the ballad and allegory, the repetition and the miraculous pregnant detail and narrative enigma. Its poetic magic owes still more to the tightness of the Shakespearean sonnet.

Indeed, if each stanza is considered an extended single line, the poem is such a sonnet. Thus it can be divided into three minutely parallel quatrains and a final surprising couplet. The poem in its quatrains develops the increasingly difficult chase and presents the convergence of the speaker's conflicting sympathies; its couplet foregrounds the fatal metamorphosis into a fine and final pun. Taken from a different angle, the poem is set in another discernible pattern; each three-line stanza is followed by a two-line stanza. This is deliberated on the part of Cummings, to shift readers back and forth between the descriptive three-line stanzas and the buzzing-with-action, two-line stanzas. Cummings is passionately mindful of how the text is laid out in order for readers to feel its dramatic immediacy.

"All in green went my love riding" offers profound evidence that the painter side of the man always co-exists with the poet. The synesthetic sensibility brought about via the verbal-visual representations Cummings fits in to contour the emotional experience in a vivid and authentic manner. From a multimodal perspective, the interactive function is realized by the size of the frame whereby readers of the poem get a medium close shot of the grand chase. With his twin obsessions in mind, Cummings crafts images that are vibrant snapshots of courtly love, hence creating a parallel of the verbally articulated romantic experience in action, image, and rhythm. In essence, each mode (either textual or visual) does not function independently in the poem; they each collaborate in the meaningmaking process. The "distance" is close enough for readers to interact with the scene. Cummings captivates readers in the storyline, drawing their attention to fine details of the chase as the poem unfolds by means of incorporating all potential lovers. The words reinforce the sense of close social proximity between the poet and his readers.

The compositional function in the poem is realized through framing and salience by virtue of parallelism, background, color differentiation, and brightness. Foregrounding is rarely an all-or-nothing-matter. Just as there are degrees of foregrounded irregularity, there are degrees of foregrounded regularity. Linguistic parallelism is very often connected with rhetorical emphasis and memorability. Every parallelism sets up a relationship of equivalence between two or more elements - the elements which are singled out as being parallel. Arguably, the importance of parallelism as a feature of 
poetic foregrounding rivals that of deviation.

There are several parallel structures evident in different parts of the poem, prompting readers to infer intra-textual semantic associations that are worthy of elaboration. First, all lines describing the deer are parallel in structure with alliterative pairs of adjectives that vary from one line to another: "swift sweet", "red rare", "lean lithe", "fleet flown", "sleek slim", and "tall tense". Here, parallelism occurs at the phonological level, with the repetition of particular sounds. These instances of parallelism create associations among the different states of the deer (the speaker's heart/hart) as the poem progresses. At first it is the "swift sweet" and later in the poem it is "tall tense" which signify a shift of state foreshadowing the tragic end it is about to meet: death (i.e., falling in love).

On a related note, all the words describing the deer are monosyllabic thus making the lines where the deer is mentioned shorter than the other lines. Again, these parallel structures are intended to constantly keep readers' eyes on the deer, which reveals itself at the end as a metaphor for the speaker's heart. Other instances of alliteration in the speaker's descriptions are "daunting death", "dappled dreams", "they than slippered sleep", "white water", and "horn at hip". Cummings makes use of these pairs to create a pleasant rhythmic effect and accentuate specific words for specific meanings. As for rhythmic effect, all the melodious sounds used in the alliterative pairs foster a pleasant relaxing mood that fits the landscape described throughout the poem. This further helps make the poem more musical and, in turn, easy to recall. This sheer fact engages the reader in the storyline the speaker is preoccupied with.

Another striking pattern of parallelism is crystal-clear in all of the even twoline stanzas (Stanzas 2, 4, 6, 8, 10, 12, and 14) where the second line of each one follows the same structure. Although the first line of each of these stanzas may signal that the scene is static, the second line of each stanza embodies a change in content and meaning, marking advancement in the hunt scene, which begins pleasantly but ends tragically as traced above. At first, the hounds are chasing the deer, and then the hounds are running in level meadows, which are peaceful. Afterwards, the hounds are before sheer peaks indicating the scene is getting serious. Finally, the target of the hunt (the speaker's heart) falls dead. Interestingly, in references such as "the level meadows ran before" and the "sheer peaks ran before", the juxtaposition of joy and sorrow, the pleasures and disappointments of a courtship are embedded in the meaning.

One last instance of parallelism in the poem that is skillfully introduced is the one between stanza 1 and stanza 5, both of which are the same in structure except for slight variations in the second line of each. While lines 2 and 3 in stanza 1 begin with prepositions for the speaker to set the scene, indicating the position of the hunter in relation to everything else in the scene, in lines 12 and 13, the speaker focuses on the action itself (the hunting-ground, so to speak) and, therefore, prepositions are not in use except for one immediately after line 14, which links directly with line 13 .

In "all in green went my love riding", the interactive function is also realized in terms of background, color differentiation, and brightness. Dramatically visual, the poem suggests in its use of myth, its courtliness, and its spatial orientation a 
medieval tapestry. Each stanza is not merely self-contained; rather, each is primarily a pictorial image. Readers witness the physical characteristics of the action - bright color and majestic places - rather than the actors' states of mind. The poem is filled with words pertaining to color.

The poem glistens with various nouns and adjectives of color that are both realistically and metaphorically used: "all in green", "horse of gold", "silver dawn", "red deer", "red roebuck", "white water", and "gold valley". This is aesthetically interwoven in the texture of the poem in different phases of the chase to foreground the beauty of the landscape surrounding the hunt. This cohesion or visual rhyme is not only used to enrich the poetic text with a sense of harmony, but also to make certain elements more salient. Packing the poem with colors serves in laying out the setting before readers' eyes making it as visual as a painting. Readers do not hear or smell anything as they read; they simply enjoy the visualized scene.

As the chase moves on, readers are taken to majestic places as though they were in a fairy tale. Interestingly, judging from the way the adjectives in the poem move from being "shiny" and "pretty" to being "violent" and "cruel", readers get a bit concerned about the end of this chase (i.e., falling in love).

\section{Conclusion}

Essentially, poets manipulate a variety of devices to encrypt and propagate their aesthetic vision and to materialize formal beauty in their verse. In "all in green went my love riding", the eccentricity of E. E. Cummings is contingent on both his adaptation of ideological content and his artistic idiosyncrasies. The multitude of devices employed by the poet serves in not only crafting a playful, inventive, and extended metaphor throughout the ballad, but in establishing structural cohesion as well. Internal cohesive deviation, being a major facet of Cummings' poetic style, fosters relief and contrast within the context of the poem which has parallel and regular constructions. Deviation is sustained to provide, through its recurrence in different shapes and forms, a level of patterning within the ballad, hence making it a moving lyrical one. In this study, the researcher attempts to showcase the division of labor among the semiotic resources employed as well as their affordances and limitations. Arguably, even with the less deviant of Cummings' love poems, like 'all in green went my love riding', not only textual cues but also visual semiotics are carriers of meaning.

\section{Directions for Future Research}

The synesthetic sensibility brought about via the verbal-visual representations Cummings fits in to contour the emotional experience in its vivacity and authenticity calls for a more fine-grained multimodal study of large corpora of his visual poetry. This study is just a point of departure, but is a crucial one. It marks the beginning of a systematic, multimodal-stylistic analysis of a good deal of 
Cummings' visual love poetry. Future research can draw on appraisal-cognitive stylistics with special regard to Appraisal Theory, Text World Theory, and Reader Response Theory.

On the one hand, an appraisal study is likely to show how relationships of solidarity are negotiated in the poem to communicate attitudes and evaluations as part of aligning audiences and creating a community of feeling. Research into interpersonal instantiations and their role in poetic discourse is comparatively sparse. The researcher argues that the systems of appraisal, namely attitude and graduation, along with their corresponding levels of delicacy allow for a more fine-grained analysis of foregrounding, especially because the poetry of E. E. Cummings celebrates a wide range of instantiations that express, negotiate, and naturalize inter-subjective positions with ideal readers.

Text World Theory in conjunction with Reader Response Theory, on the other hand, would pinpoint how and why readers construct peculiar discourselevel mental representations in the course of reading poetry. A text-world approach to "extended metaphor foregrounding" in "all in green went my love riding" is an insightful endeavor to account for how individual clause-level metaphors combine along the stanzas of the poem to create a discourse-level conceptual structure. The source-worlds of extended metaphors are anchored in the text-worlds structures, in the twists and turns of the narrative perspective and, if foregrounded in the mental representations of the discourse participants, they would give rise to subtle conceptual effects that are worthy of scrutiny.

\section{References}

Alfandary I (2002) E. E. Cummings ou la Minuscule Lyrique. Paris: Belin.

Berutti BR (1970) A Grammatical Analysis of the Poetry of E. E. Cummings. PhD Thesis, University of Texas, USA.

Cureton R (1979a) The Aesthetic Use of Syntax: Studies on the Syntax of the Poetry of E. E. Cummings. $\mathrm{PhD}$ Thesis, University of Illinoi, USA.

Cureton R (1979b) E. E. Cummings: A Study of the Poetic use of Deviant Morphology. Poetics Today 1(1/2): 213-244.

Cureton R (1986) Visual form in E. E. Cummings No Thanks. Word and Image 2(3): 247277.

Espák GT (2012) Precision Poetry by Canonical Cummings: "1×1" Hungarian Journal of English and American Studies 18(1/2): 293-304.

Fairley I (1971) Syntactic Deviance in the Poetry of E. E. Cummings. PhD Thesis, Harvard University, USA.

Fairley I (1975) E. E. Cummings and Ungrammar: A Study of Syntactic Deviance in his Poems. New York: Watermill.

Friedman N (1960) E. E. Cummings: The art of His Poetry. Baltimore: Johns Hopkins UP.

Halliday MAK (1978) A Language as a Social Semiotic. London: Arnold.

Halliday MAK (2007) Language and Education. London: Continuum.

Halliday MAK, Matthiessen CMIM (2014) An Introduction to Functional Grammar. London: Arnold.

Heusser M (1997) I Am My Writing: the Poetry of E. E. Cummings. Tubingen: Stauffenburg. 
Vol. 5, No. $4 \quad$ Elyamany: Decoding the Narrative Structure of E. E. Cummings'...

Jewitt C (2005) Technology, Literacy and Learning: A Multimodal Approach. London: Routledge.

Kidder RM (1979) Cummings and Cubism: The Influence of the Visual Arts on Cummings' Early Poetry. Journal of Modern Literature 7(2): 255-291.

Kress G, van Leeuwen T (1996) Reading Images: The Grammar of Visual Design. New York: Routledge.

Kress G, van Leeuwen T (2006) Reading Images: The Grammar of Visual Design, $\left(2^{\text {nd }}\right.$ Edn.). London: Taylor and Francis.

Leech G (1969) A Linguistic Guide to English Poetry. London: Longman.

Leech G Short M (1981) Style in Fiction. London: Longman Group Ltd.

Leech G Short M (2007) Style in Fiction: a Linguistic Guide to English Fictional Prose. London: Pearson Education.

Leech G (2008) Language in Literature: Style and Foregrounding. Harlow: Pearson Longman.

Lord JB (1966) Paragrammatical Structure in a Poem of E. E. Cummings. Pacific Coast Philology 1: 66-73.

Miall DS, Kuiken D (1994) Foregrounding, Defamiliarization, and Affect: Response to Literary Stories. Poetics 22(5): 389-407.

Moe A (2011) Cummings's Urban Ecology: An Exploration of EIMI, No Thanks, and the Cultivation of the Ecological Self. Interdisciplinary Studies in Literature and Environment 18(4): 737-762.

O'Halloran K (2011) Multimodal Representation and Knowledge. London: Routledge.

Short M (1996) Exploring the Language of Poems, Plays and Prose. London: Longman.

Tartakovski R (2009) E. E. Cummings' Parentheses: Punctuation as Poetic Device. Style, 43(2): 215-247.

van Peer W (1986) Stylistics and Psychology: Investigations of Foregrounding. London: Croom Helm.

van Peer W (1987) Top-down and Bottom-up: Interpretative Strategies in Reading E. E. Cummings. New Literary History 18(3): 597-609.

von Abele R (1955) Only to Grow: Change in the Poetry of E. E. Cummings. PMLA 70(5): 913-933.

Webster M (1995) Reading Visual Poetry after Futurism: Marinetti, Apollinaire, Schwitters, Cummings. New York: Peter Lang.

Wang X (2012) A Study of Visual Poem "in Just-" from the Perspective of Multimodal Discourse Analysis. Theory and Practice in Language Studies 2(12): 2649-2654. 


\section{Appendix A \\ E. E. Cummings' "all in green went my love riding"}

All in green went my love riding

on a great horse of gold

into the silver dawn.

Four lean hounds crouched low and smiling the merry deer ran before.

Fleeter be they than dappled dreams

the swift sweet deer

the red rare deer.

Four red roebuck at a white water the cruel bugle sang before.

Horn at hip went my love riding

riding the echo down

into the silver dawn.

Four lean hounds crouched low and smiling the level meadows ran before.

Softer be they than slippered sleep

the lean lithe deer

the fleet flown deer.

Four fleet does at a gold valley

the famished arrow sang before.

Bow at belt went my love riding

riding the mountain down

into the silver dawn.

Four lean hounds crouched low and smiling the sheer peaks ran before.

Paler be they than daunting death

the sleek slim deer

the tall tense deer.

Four tall stags at the green mountain

the lucky hunter sang before.

All in green went my love riding

on a great horse of gold

into the silver dawn.

Four lean hounds crouched low and smiling my heart fell dead before. 
